\title{
Emendation of Bacteroidaceae and Butyrivibrio and Descriptions of Desulfomonas gen. nov. and Ten New Species in the Genera Desulfomonas, Butyrivibrio, Eubacterium, Clostridium, and Ruminococcus
}

\author{
W. E. C. MOORE, J. L. JOHNSON, AND L. V. HOLDEMAN \\ Anaerobe Laboratory, Virginia Polytechnic Institute and State University, Blacksburg, Virginia 24061
}

\begin{abstract}
The family Bacteroidaceae is emended to include bacteria that are monotrichous or lophotrichous. The genus Butyrivibrio is emended to include lophotrichous bacteria. Desulfomonas, a new genus of nonmotile, nonsporeforming, gram-negative, anaerobic, sulfate-reducing rods, and 10 new species of anaerobes, Desulfomonas pigra, Butyrivibrio crossotus, Ruminococcus gnavus, $R$. lactaris, $R$. obeum, Eubacterium dolichum, E. hadrum, E. ramulus, E. siraeum, and Clostridium leptum, are described. These species have been isolated from human intestinal contents or from human feces. The type strains of these species are ATCC 29098, 29175, 29149, 29176, 29174, 29143, 29173, 29099, 29066, and 29065 , respectively.
\end{abstract}

During studies of the bacteria from the feces and the contents of the gastrointestinal tracts of humans, cultures of several previously undescribed species that are predominant among the bacteria in the intestines of some individuals were isolated. Species for which we have 10 or more isolates from six or more individuals are described below. These isolates were from studies of 177 specimens from 90 individuals. Discussion of the incidence of most of these species, as compared with other kinds of organisms of the intestinal flora, is published elsewhere $(3,9)$.

\section{MATERIALS AND METHODS}

The organisms described in this report were isolated and characterized according to anaerobic-tube culture methods and procedures published previously $(4,5,9,11,12)$. Single colonies were picked from rumen fluid-glucose-cellobiose agar (RGCA) roll tubes, inoculated with dilutions of feces or intestinal contents, after incubation for 5 days under oxygen-free carbon dioxide. After one or more streaking and picking series, to verify a pure culture, fermentative and biochemical characteristics in prereduced media (5) were determined.

To determine hemolytic activity, cultures were streaked on freshly prepared blood agar plates (BAP) of brain heart infusion agar supplemented (per $100 \mathrm{ml}$ ) with $0.5 \mathrm{~g}$ of yeast extract, $0.1 \mu \mathrm{l}$ of vitamin $\mathrm{K}_{1}, 0.5 \mathrm{mg}$ of hemin (BHIA-S), and $5.0 \mathrm{ml}$ of defibrinated sheep blood. Inoculated BAP were incubated 40 to $48 \mathrm{~h}$ in a vented GasPak (BBL) anaerobe jar with a gaseous atmosphere of $90 \% \mathrm{H}_{2}-10 \%$ $\mathrm{CO}_{2}$. Reactions on egg yolk agar (EYA) medium (5) were determined after similar incubation.

The moles percent guanine plus cytosine $(\mathrm{G}+\mathrm{C})$ contents of the deoxyribonucleic acid (DNA) preparations were determined by the thermal melting point $\left(T_{m}\right)$ method (8) by using an automatic recording spectrophotometer (Gilford Instrument Laboratories). DNA from Escherichia coli B was included in each set of analyses as a standard.

\section{RESULTS AND DISCUSSION}

Members of the following new taxa were isolated from the intestinal contents or feces of humans.

Desulfomonas gen. nov. and D. pigra sp. nov. Desulfomonas gen. nov. (De.sul.fo.mo'nas. L. pref. de from; L. n. sulfur sulfur; Gr. fem. n. monas unit; M. L. fem. n. Desulfomonas a cell that reduces sulfur compounds). This genus includes the obligately anaerobic, straight, nonmotile, gram-negative, nonsporeforming, sulfate-reducing rods. The metabolic activity, utilization of pyruvate to produce acetate, reduction of sulfate, presence of cytochrome, and relatively high moles percent $\mathrm{G}+\mathrm{C}$ content of the DNA, indicate that the genus is probably phylogenetically related to Desulfovibrio and Desulfotomaculum. However, those genera are classified according to morphological properties (cell shape and polar flagella, or production of spores) not exhibited by the presently described organisms. Therefore, we place the genus Desulfomonas in the family Bacteroidaceae pending more information that might relate the three morphologically distinct, sulfate-reducing genera in a single higher taxon, possibly at the family level.

Desulfomonas pigra sp. nov. (L. adj. pig'ra 
lazy [referring to the limited substrate utilization of the species]); type species of the genus. Obligately anaerobic, nonsporeforming, nonmotile, gram-negative rods that are straight to slightly curved and have rounded ends (Fig. 1). From PY-glucose (5) broth cultures, cells were about 0.8 to $1.0 \mu \mathrm{m}$ wide and 2.5 to $10.0 \mu \mathrm{m}$ long.

Colonies. After incubation for 5 days in RGCA roll tubes, subsurface colonies were 0.5 $\mathrm{mm}$ in diameter, lenticular, and translucent to opaque, sometimes with a dark halo that might have been produced by $\mathrm{H}_{2} \mathrm{~S}$. Surface colonies on BHIA-S roll streaks on anaerobically incubated BAP were 1 to $2 \mathrm{~mm}$ in diameter, circular to slightly irregular, low convex or umbonate, and translucent. There was no reaction on EYA and no hemolytic activity.

Cultural characteristics. Most broth cultures showed moderate growth $(2+)$ with turbidity and a small amount of smooth sediment. Growth was greatly enhanced (4+) in PY-pyruvate broth, and pyruvate seemed to serve as an energy source. The best growth was obtained at $37 \mathrm{C}$, although some strains would grow at 30 and $45 \mathrm{C}$.

Biochemical reactions. Characteristics of 11 isolates of this species are given in Table 1. In addition, the type strain and five other strains tested did not ferment adonitol, galactose, glycerol, inulin, sorbose, or dextrin. None of the six strains produced ammonia in PY or choppedmeat (CM) broth cultures. However, the type strain and two other strains tested produced ammonia from PY-urea broth cultures, and the $\mathrm{pH}$ was increased 0.3 to 0.7 of a $\mathrm{pH}$ unit. These three tested strains did not produce oxidase. None of the 11 strains reduced nitrate.

The type strain was tested for metabolic activity in several media. Little or no growth was produced in the absence of peptone in glucosemineral salts-biotin medium (5) reduced with cysteine, nor was $\mathrm{H}_{2} \mathrm{~S}$ or $\mathrm{H}_{2}$ produced. In peptone-Trypticase-yeast extract medium with or without glucose, growth was poor, about $0.3 \%$ $\mathrm{H}_{2}$ was produced in the head space gas, and small amounts of acetic and succinic acids and large amounts of $\mathrm{H}_{22} \mathrm{~S}$ (as evidenced by immediate solid black color with the addition of saturated ferrous sulfate solution) were produced. Formate and fumarate did not affect growth or hydrogen or $\mathrm{H}_{2} \mathrm{~S}$ production. The reactions observed in these media were unaffected by the addition of $20 \mathrm{mM} \mathrm{MgSO}{ }_{4}$ as compared with $0.07 \mathrm{mM} \mathrm{MgSO}_{4}$ in the usual media.

The higher level of $\mathrm{MgSO}_{+}$did affect the reactions of all three strains tested in pyruvate medium. Pyruvate utilization increased from

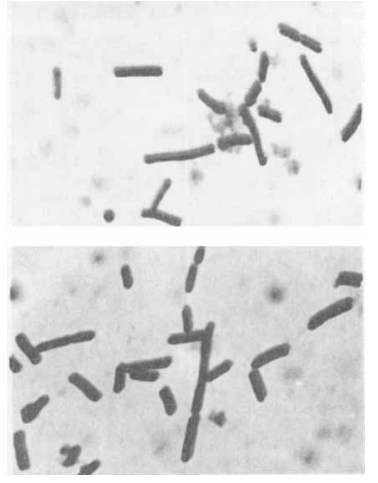

Fig. 1. Desulfomonas pigra ATCC 29098. Top, Cells from $P Y$ broth culture. Bottom, Cells from $P Y$ glucose broth culture. See Fig. 11 for scale.

an average of 53 to $80 \%$, while hydrogen production decreased from over $3 \%$ to less than $0.3 \%$ in the head space gas. Acetate production increased about fourfold. Probable increases in cell yield and $\mathrm{H}_{2} \mathrm{~S}$ production were obscured because they were very high in both media. The high level of $\mathrm{MgSO}_{4}$ improved lactate utilization and markedly decreased hydrogen production from lactate by the type strain, but little or no effect was demonstrated in lactate with the other two strains tested. These data indicate that the organism reduces sulfate but produces hydrogen in its absence, that high levels of $\mathrm{H}_{2} \mathrm{~S}$ are produced from peptone and/or cysteine and from sulfate, and that energy metabolism is inhibited in the absence of sulfate as a hydrogen acceptor.

The presence of cytochrome in cells of the type strain was demonstrated by J. F. Sperry by comparing the absorption spectra of dithionate-reduced samples of broken, washed cells against air-oxidized samples. Absorption maxima were at 425,527 , and $556 \mathrm{~nm}$ and a minimum was at $450 \mathrm{~nm}$. Addition of $2 \mathrm{~N} \mathrm{NaOH}$ to a cellular pellet showed a red fluorescence, indicating the presence of desulfoviridin, as reported in other sulfate-reducing bacteria.

Fermentation products. Fermentation products (average milliequivalents per $100 \mathrm{ml}$ of culture with $0.07 \mathrm{mM} \mathrm{MgSO}$ ) were as follows.

From PY-pyruvate: Acetate (6.0), sometimes with trace to moderate amounts of lactate, succinate, or formate. Copious hydrogen was produced.

From PY or PY-glucose: Acetic acid (1.0).

From PY-fructose cultures: Small amounts of hydrogen, presumably from the PY, were detected.

$G+C$ content of the DNA. The $\mathrm{G}+\mathrm{C}$ content is $67 \mathrm{~mol} \%$ by $T_{m}$ for the type strain and 66 mol\% for one other strain (A2-24D) tested. 


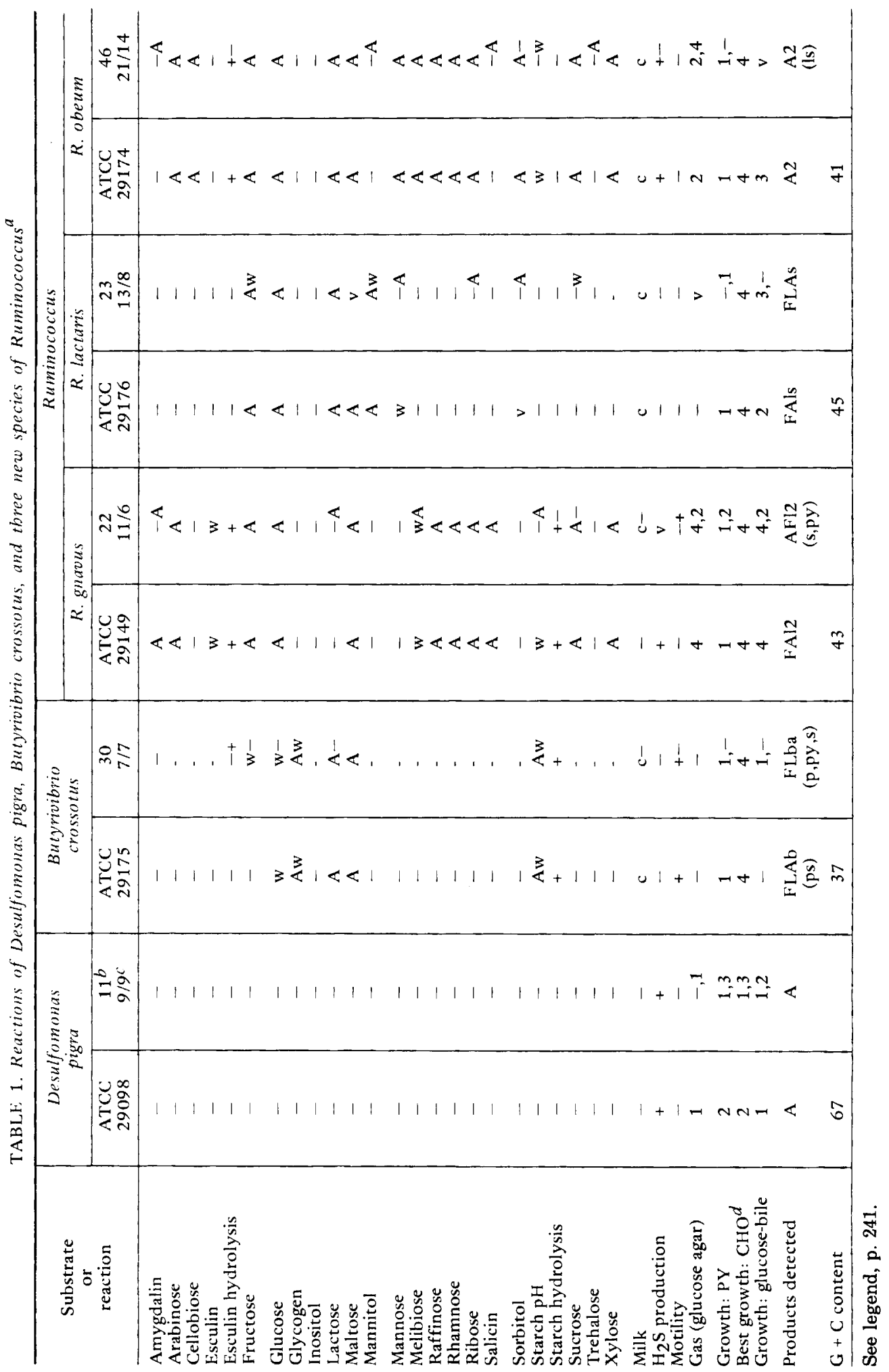




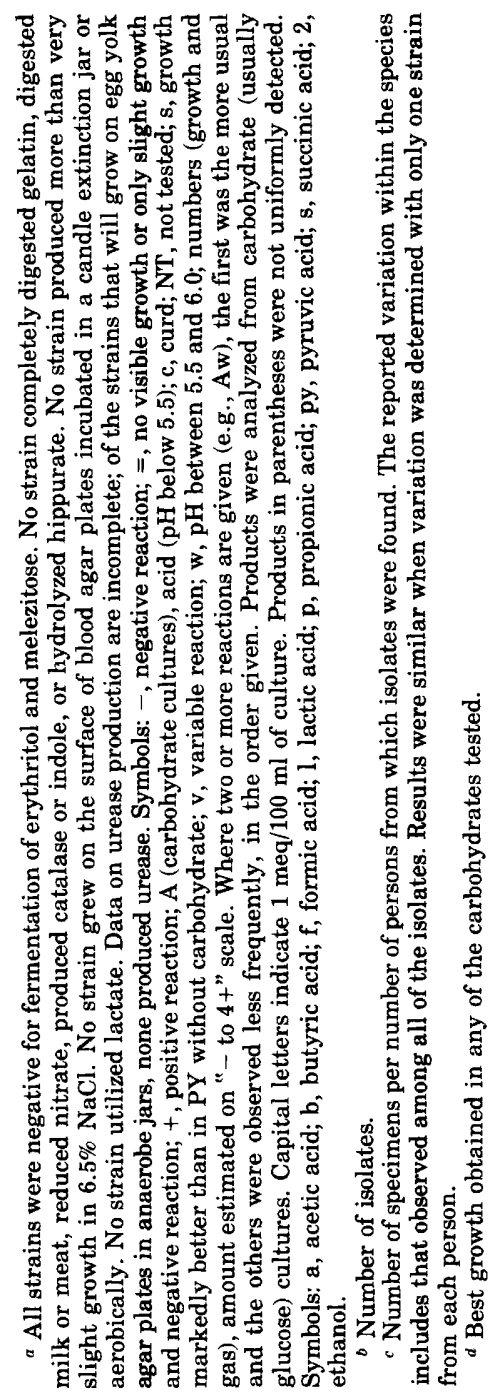

Type strain. The type strain is American Type Culture Collection (ATCC) 29098 (= Virginia Polytechnic Institute [VPI] C3-23); isolated from human feces.

Comments. This group was described previously (9) as Bacteroides L-3.

Strains placed in this species are: A2-24D, A18-14, B6-30C, C3-23, C32-31, and S9-39 from feces; M3-381 from the contents of a transverse colon; and 9021 from a ruptured sigmoid colon. Other isolates were from similar sites. With routine tests $D$. pigra superficially appears to be similar to $B$. corrodens and other anaerobic nonfermentative, gram-negative rods. However, it differs from them by not reducing nitrate, not producing oxidase, and by producing $\mathrm{H}_{2} \mathrm{~S}$ and converting pyruvate to large amounts of acetate and hydrogen. Hydrogen production is decreased in the presence of large amounts $(20 \mathrm{mM})$ of $\mathrm{MgSO}_{4}$. The $\mathrm{G}+\mathrm{C}$ content of the DNA of $D$. pigra is 66 to $67 \mathrm{~mol} \%$, whereas that of $B$. corrodens is 28 to $30 \mathrm{~mol} \%$ (6).

This species of anaerobic, nonsporeforming, gram-negative, nonmotile, sulfate-reducing rods is placed in the new genus Desulfomonas rather than the existing sulfate-reducing genus Desulfotomaculum or Desulfovibrio because spores could not be detected in basal medium or in glucose or pyruvate cultures by spore stain or by survival of cultures at $80 \mathrm{C}$ for $10 \mathrm{~min}, 70 \mathrm{C}$ for $10 \mathrm{~min}$, or in $70 \%$ alcohol for 1 h. Neither motility nor flagella could be demonstrated in any cultures.

Emendation of Butyrivibrio; B. crossotus sp. nov. The genus Butyrivibrio currently includes the single species $B$. fibrisolvens, and the genus is described on the basis of this monotrichous species. During our studies of the intestinal bacteria, one group was detected which is similar to $B$. fibrisolvens in that the organisms are anaerobic, gram-negative, curved rods that are saccharolytic and grow poorly or not at all without a fermentable carbohydrate, from which formic, butyric, lactic, and acetic acids are produced. These strains, however, are lophotrichous (Fig. 2), unlike strains of $B$. fibrisolvens, which either are monotrichous or occasionally have two polar flagella. Although other individual properties distinguish the new species from $B$. fibrisolvens, we believe that the major characteristics are so similar as to place the organism in the same genus with $B$. fibrisolvens. We do not believe that the number of polar flagella is a sufficiently important characteristic to warrant the creation of a new genus, particularly since individual strains of bacteria with polar flagella vary in respect to numbers of flagella. Therefore, we propose an emended 


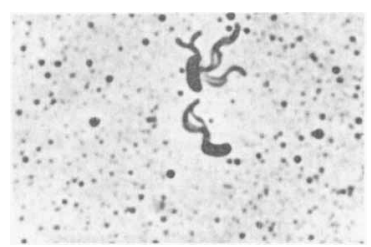

FIG. 2. Butyrivibrio crossotus ATCC 29175. Lophotrichous cells. See Fig. 11 for scale.

description of the genus Butyrivibrio to include curved rods which occur singly or in chains or filaments and which may or may not be helical. Cells are motile, monotrichous or lophotrichous, with polar or subpolar flagella; nonmotile variants may occur. No resting stages are known. Cells are gram negative. Metabolism is fermentative, carbohydrates being the main fermentable substrates, with the production of butyrate as one of the important products. Strains are strictly anaerobic.

Butyrivibrio crossotus sp. nov. (Gr. adj. cross.so'tus tasseled [referring to the multiple polar or subpolar flagella]). Cells are obligately anaerobic, lophotrichous (polar or subpolar), nonsporeforming, gram-negative rods with rounded to slightly tapered ends. Cells were usually curved, at least soon after isolation from the natural habitat, and occurred singly or in pairs and short chains (Fig. 2 and 3). Pairs were often in an "S" arrangement. From PYG broth cultures, cells were 0.5 to $0.7 \mu \mathrm{m}$ wide and 2.0 to $5.0 \mu \mathrm{m}$ long. Three of 29 isolates tested were nonmotile, and no flagella could be seen in flagella stains from several subcultures; however, they had the other characteristics typical for this species, and they are probably nonmotile variants. However, it is also possible that the flagella were broken off during preparation of the suspension for flagella staining.

Colonies. After incubation for 5 days in RGCA roll tubes, subsurface colonies were 0.5 to $1.0 \mathrm{~mm}$ in diameter, lenticular, and translucent to transparent. Surface colonies on BHIA$\mathrm{S}$ roll streaks were 0.2 to $1.0 \mathrm{~mm}$ in diameter, circular, entire, convex, translucent to semiopaque, and smooth. Only 3 of the 10 strains tested grew as surface colonies on BAP incubated anaerobically; surface colonies were the same as on the BHIA-S roll streaks, and no hemolytic activity was observed. The few strains that grew on EYA produced no lecithinase or lipase reaction.

Cultural characteristics. There was poor growth in PY broth that did not contain a fermentable carbohydrate. PY-maltose cultures had abundant growth with smooth, flocculent, or ropy sediment; there usually was some turbidity.

The optimum temperature for growth was $37 \mathrm{C}$. Some strains grew equally well at $45 \mathrm{C}$. There was either no growth or very poor growth at $30 \mathrm{C}$.

Biochemical reactions. Some of the biochemical characteristics of 31 isolates of this species are given in Table 1. In addition, the type strain and nine other strains tested did not grow well in, or ferment, adonitol, galactose, glycerol, inulin, or sorbose. All produced acid in PY-dextrin. There was little or no growth in PY media containing lactate, pyruvate, or threonine. No ammonia was detected from PY or CM cultures (with Nessler reagent).

After incubation for 5 days, the $\mathrm{pH}$ was 4.7 to 5.2 in the PY-maltose cultures.

Fermentation products. Fermentation products (average milliequivalents per $100 \mathrm{ml}$ of culture) were as follows.

From PY-maltose: Formic (2.0), D-(-)-lactic (1.2), and butyric (0.85) acids, sometimes with traces of propionic, pyruvic, or succinic acids. No hydrogen was detected from PY-maltose cultures.

From PY: No acid products or only trace amounts of acetic or butyric acid. In all cultures, the original small levels of acetate in the medium were unchanged or were only very slightly increased.

$G+C$ content of the DNA. The $\mathrm{G}+\mathrm{C}$ content is $37 \mathrm{~mol} \%$ by $T_{m}$ for the type strain and 36 mol\% for the one other strain (C38-24) tested.

Type strain. The type strain is ATCC 29175 (= VPI T9-40A); isolated from human feces.

Comments. Characteristic of this species, in addition to the curved lophotrichous rods, was the requirement for a fermentable carbohy-

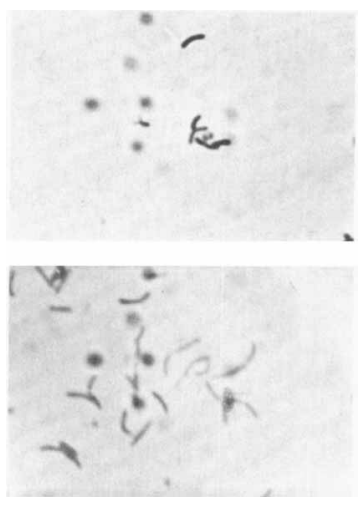

FIG. 3. Butyrivibrio crossotus ATCC 29175. Top, Cells from PY broth culture. Bottom, Cells from $P Y$ maltose broth culture. See Fig. 11 for scale. 
drate (e.g., maltose, starch, glycogen, or dextrin) for growth, and the production of formic, lactic, and butyric acids. Growth with lactose and fermentation of lactose were variable. Glucose slightly stimulated growth, but it was only weakly fermented if at all. Curd was produced in milk by those strains that use lactose most readily.

All of the strains of this species were isolated from human feces or rectal contents. They included A15-11, C37-58B, C38-24, A13-53, T940A, S4B-51B, and M2-203.

Emendation of Bacteroidaceae. Currently the family Bacteroidaceae is restricted to gramnegative, anaerobic, nonsporeforming rods that are either nonmotile or are motile and peritrichous. The restriction concerning the arrangement of flagella excludes a number of genera that have no other obvious family association. They include Butyrivibrio, Succinivibrio, Succinomonas, Lachnospira, Selenomonas, and Desulfovibrio. The establishment of a distinct family for a comparable group of bacteria with polar flagella has precedent in the family $V i$ brionaceae.

However, the usefulness of flagellar arrangement for family, genus, or even species differentiation often breaks down in view of nonmotile variants that are known to occur within well-described species, as well as among different motile and nonmotile species that exhibit obvious similarities of general major properties like metabolic activity or chemical composition. Attempts to determine family groups on the basis of moles percent $\mathrm{G}+\mathrm{C}$ also lead to difficulty because of the wide range of values found within genera, e.g., Bacteroides, 28 to 66 mol\%; Fusobacterium, 26 to $66 \mathrm{~mol} \%$; or Desulfovibrio, 46 to $61 \mathrm{~mol} \%$. Apparently, information that would indicate phylogenetic relationships among the bacteria is either not available or is being misinterpreted. Perhaps we are misled by considering as "important" those characteristics with which we are most familiar, which are easily measured, or which produce clear-cut results. Nevertheless, there are many properties associated with the Gram reaction, and this suggests that it should correlate with phylogenetic relationships. There are also numerous correlations with metabolic pathways and energy metabolism. There seem to be fewer additional characteristics that correlate with flagellar arrangement or spore production, but moles percent $\mathrm{G}+\mathrm{C}$ values suggest that there is some validity in relating these characteristics to a phylogenetic scheme.

Until new types of information become available to more clearly indicate true phylogenetic relationships among these bacteria, we propose a more utilitarian classification on the basis that its usefulness will aid the acquisition of more complete information that may reveal phylogenetic relationships.

We propose that the definition of the family Bacteroidaceae be emended to include: the genera of gram-negative, anaerobic, nonsporeforming, straight, curved or filamentous rods, that are either nonmotile or motile and peritrichous, monotrichous, or lophotrichous. We further propose that the family Bacteroidaceae be expanded to include not only Bacteroides (the type genus), Fusobacterium, Leptotrichia, and the new genus Desulfomonas but also Butyrivibrio, Succinivibrio, Lachnospira, Selenomonas, and Desulfovibrio.

Other new species. Ruminococcus gnavus sp. nov. (L. adj. gna'vus [na'vus] busy, active [referring to the active fermentative ability of this species]). Obligately anaerobic, nonsporeforming, nonmotile or motile with one to three flagella, gram-positive cocci that occur in chains or pairs. Cells were often slightly elongate with slightly tapered ends (Fig. 4). From PY-glucose broth cultures, cells were about 0.9 to 1.1 by 1.1 to $1.4 \mu \mathrm{m}$ in size. Although cells decolorized easily in Gram stains from older cultures, they usually were frankly gram-positive in 24-h-old cultures.

Colonies. After incubation for 5 days in RGCA roll tubes, subsurface colonies were 0.5 to $3.0 \mathrm{~mm}$ in diameter, lenticular, and transparent to translucent. Surface colonies on BHIA-S roll streaks or anaerobically incubated BAP were 0.5 to $3.0 \mathrm{~mm}$ in diameter, circular, entire, flat to convex, and translucent to opaque. There was no reaction on EYA and no hemolytic activity.

Cultural characteristics. In PY broth containing a fermentable carbohydrate, there was abundant growth with turbidity and a smooth

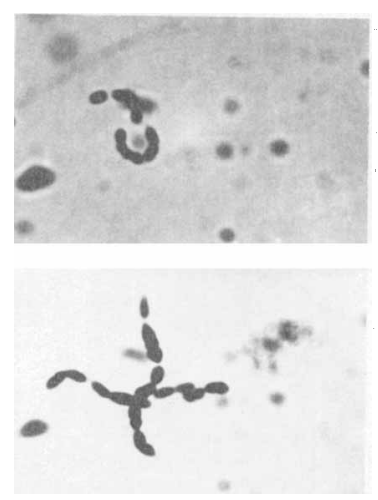

Fig. 4. Ruminococcus gnavus ATCC 29149. Top, Cells from PY broth culture. Bottom, Cells from PYglucose broth culture. See Fig. 11 for scale. 
to stringy sediment. There was only slight, if any, turbidity, in PY broth without a fermentable carbohydrate. Best growth was obtained at $37 \mathrm{C}$; however, most strains produced some growth at 30 and at $45 \mathrm{C}$.

Biochemical reactions. Some of the biochemical characteristics of 23 isolates of this species are reported in Table 1 . In addition, the type strain and six other strains tested fermented both galactose and inulin, some weakly fermented dulcitol, and none fermented adonitol, glycerol, or sorbose. Ammonia was not produced in $\mathrm{PY}$ or in CM cultures.

In PY-glucose cultures, the $\mathrm{pH}$ was 4.8 to 5.2 after incubation for 1 to 2 days.

Fermentation products. Fermentation products (average milliequivalents per $100 \mathrm{ml}$ of culture) were as follows.

From PY-glucose: Acetic acid (2.9), formic acid (2.3), ethanol, and small amounts of lactic acid. Succinic and pyruvic acids were sometimes detected.

From PY-pyruvate: Acetate (6.0), formate (4.0), lactate (0.3), and ethanol; a small amount of succinate was sometimes detected.

From PY-gluconate: Acetate (3.9), formate (3.0), lactate (0.5), and ethanol; succinate was sometimes detected.

From PY-broth: Trace to moderate amounts of acetic, formic, and lactic acids, along with ethanol, were usually present; succinic and pyruvic acids were sometimes detected.

From PY-fructose, copious hydrogen was produced.

$G+C$ content of the DNA. The $\mathrm{G}+\mathrm{C}$ content of the DNA is $43 \mathrm{~mol} \%$ for the type strain and for the one other strain (S6C-5) tested.

Type strain. The type strain is ATCC 29149 (= VPI C7-9); it was isolated from human feces.
Comments. This organism was previously described (9) under the designation Ruminococcus $\mathrm{AB}$.

The strains placed in this species include: $\mathrm{C} 7-$ 57, J12-6A, S6C-5, and C53-51, from feces; M3590 , from the contents of an ascending colon; and M5-193, from scrapings of a jejunal wall. A strain of this species was also isolated from the stomach wall scrapings, the duodenal wall scrapings, and the contents of the descending colon and rectum of one individual (M5).

This species of anaerobic, gram-positive cocci is placed in the genus Ruminococcus because its growth is quite markedly enhanced by a fermentable carbohydrate and because its fermentation products include acetic and formic, but not butyric, acids. The $\mathrm{G}+\mathrm{C}$ content of the DNA of this species $(43 \mathrm{~mol} \%)$ is within the range (40 to $45 \mathrm{~mol} \%$ ) reported previously for species in the genus Ruminococcus $(5,10)$.

$R$. gnavus is recognized by its highly fermentative nature, the carbohydrates fermented, and the production of ethanol, acetic, and formic acids in large quantities. A key for the presumptive differentiation of species in this genus is given in Table 2.

Ruminococcus lactaris sp. nov. (L. adj. lac.ta'ris milk-drinking [referring to its rapid fermentation of lactose and curding of milk]). Obligately anaerobic, nonsporeforming, nonmotile, gram-positive cocci and ellipsoidal cells that usually occur in long chains (Fig. 5). From PY-glucose broth cultures, cells were about 0.4 to 0.7 by 0.4 to $1.2 \mu \mathrm{m}$ in size. Cells usually stained gram positive from 24 -h-old broth cultures; however, a few gram-negative cells were sometimes seen in chains of predominantly gram-positive cells. Cells of unequal size were often present in the same chain.

TABLE 2. Key for presumptive differrentiation of described species of Ruminococcus

\begin{tabular}{|c|c|c|c|c|c|c|}
\hline \multicolumn{5}{|c|}{ Fermentation of: } & \multirow{2}{*}{$\begin{array}{l}\text { Fermentation prod- } \\
\text { ucts }\end{array}$} & \multirow{2}{*}{ Suggested species } \\
\hline Cellobiose & Arabinose & Mannitol & Lactose & Maltose & & \\
\hline \multirow[t]{4}{*}{$+a$} & + & & & & $\mathrm{A} 2(1, \mathrm{~s})^{b}$ & R. obeum \\
\hline & - & & & + & $\mathrm{SA}(\mathrm{Fl}, \mathrm{py})$ & R. callidus \\
\hline & & & & - & $\mathrm{ASF}(1)$ & R. flavefaciens \\
\hline & & & & & $\mathrm{A} 2(\mathrm{fsl})$ & R. albus \\
\hline \multirow[t]{4}{*}{-} & + & & & & FAl2 & $R$. gnavus \\
\hline & - & + & & & FLAs & R. lactaris \\
\hline & & - & + & & $\mathrm{La2}(\mathrm{fs})$ & R. torques \\
\hline & & & - & & a2(lfpb) & R. bromii \\
\hline
\end{tabular}

${ }^{a}+$, Carbohydrate fermented; - , carbohydrate not fermented.

${ }^{b}$ a, Acetic acid; b, butyric acid; f, formic acid; l, lactic acid; $p$, propionic acid; py, pyruvic acid; s, succinic acid; 2, ethanol. Capital letters indicate $1 \mathrm{meq}$ (or more) per $100 \mathrm{ml}$ of culture; small letters indicate less than $1 \mathrm{meq} / 100 \mathrm{ml}$ of culture. Products in parentheses are not uniformly detected. 


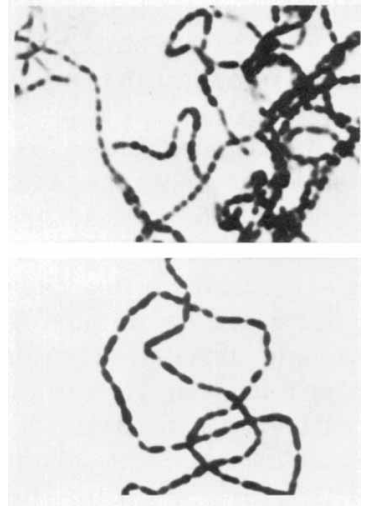

FIG. 5. Ruminococcus lactaris ATCC 29176. Top, Cells from PY broth culture. Bottom, Cells from PYglucose broth culture. See Fig. 11 for scale.

Colonies. After incubation for 5 days in RGCA roll tubes, subsurface colonies were 0.5 to $1.0 \mathrm{~mm}$ in diameter, tan to white, lenticular to bifoliate, and translucent to opaque. Surface colonies on BHIA-S roll streaks and anaerobically incubated blood agar plates were 1 to 3 $\mathrm{mm}$ in diameter, circular, entire to erose, translucent to opaque, sometimes with dark centers. There was no reaction on EYA or hemolytic activity.

Cultural conditions. In PY broth cultures with a fermentable carbohydrate, there was abundant growth with turbidity and a flocculent or stringy sediment. Growth was often enhanced by the addition of $0.02 \%$ Tween 80 . The temperature for optimal growth was $37 \mathrm{C}$; most strains grew well at $45 \mathrm{C}$; some grew well at $30 \mathrm{C}$.

Biochemical reactions. The biochemical characteristics of 23 isolates of this species are reported in Table 1 . In addition, the type strain and seven other strains tested produced acid from galactose but did not ferment adonitol, glycerol, inulin, or sorbose. Ammonia was not produced in PY or in CM broth cultures. Urease was not detected.

After incubation for 1 to 3 days, the $\mathrm{pH}$ in PY-glucose was 5.0 to 5.5.

Fermentation products. Fermentation products (average milliequivalents per $100 \mathrm{ml}$ of culture) were as follows.

From PY-glucose: Formic (1.5), lactic (1.3), acetic (1.2), and small amounts of succinic acids.

From PY-pyruvate: Acetate (2.9); formate (1) was usually detected.

From PY-broth: Only small amounts of acetic, lactic, or succinic acids were detected.

Moderate to abundant hydrogen was produced in PY-fructose cultures.
$G+C$ content of the DNA. The $\mathrm{G}+\mathrm{C}$ content of the DNA is $45 \mathrm{~mol} \%$ by $T_{m}$ for the type strain and for the one other strain (R2-33) tested.

Type strain. The type strain is ATCC 29176 (= VPI X6-29); it was isolated from human feces.

Comments. Of the 23 isolates that we have, 22 were from human feces. The strains placed in this species include A16-18, C31-39, C45-15, C47-34, R2-33, S6D-49, and X6-29 from feces and M3-211 from duodenal contents.

This species of anaerobic, gram-positive cocci is placed in the genus Ruminococcus because its fermentation products include combinations of acetic, formic, succinic, and lactic acids, because growth is markedly enhanced by the presence of a fermentable carbohydrate, and because its $\mathrm{G}+\mathrm{C}$ content $(45 \mathrm{~mol} \%)$ is within the range reported for other species in the genus. Hydrogen production also appears to be a constant characteristic of species in this genus.

$R$. lactaris typically forms long chains of cells in a carbohydrate medium. The production of acetic, formic, and lactic acids and the specific carbohydrates fermented differentiate this species from others in the genus (Tables 1 and 2).

Ruminococcus obeum sp. nov. (Gr. $\mathrm{n}$. o'be.um egg [referring to the ovoid shape of the cells]). Obligately anaerobic, nonsporeforming, nonmotile, gram-positive cocci occurring in pairs or in chains of pairs of pointed ellipsoidal cells. Dividing cells often give the appearance of short rods with pointed ends (Fig. 6). From PY-glucose broth cultures, cells were about 0.8 to $1.1 \mu \mathrm{m}$ by 0.9 to $1.5 \mu \mathrm{m}$ in size.

Colonies. After incubation for 5 days in RGCA roll tubes, subsurface colonies were 0.5 to $2.0 \mathrm{~mm}$ in diameter, lenticular, translucent to opaque, and sometimes tan. Surface colonies on BHIA-S roll streaks were 1 to $3 \mathrm{~mm}$ in

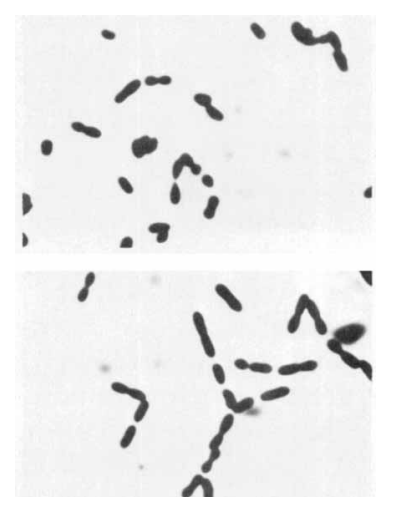

FIG. 6. Ruminococcus öbeum ATCC 29174. Top, Cells from $P Y$ broth culture. Bottom, Cells from $P Y$ glucose broth culture. See Fig. 11 for scale. 
diameter, lenticular, and translucent to opaque. There was no reaction on EYA and no hemolytic activity.

Cultural characteristics. Growth was poor in PY broth without a fermentable carbohydrate. Broth cultures with a fermentable carbohydrate had abundant growth and were turbid with copious sediment. Addition of $0.02 \%$ Tween 80 did not markedly affect growth. The optimum temperature for growth was $37 \mathrm{C}$. Most strains grew well at $30 \mathrm{C}$; growth was poor at 25 and $45 \mathrm{C}$.

Biochemical reactions. The biochemical characteristics of 46 isolates of this species are given in Table 1 . In addition, the type strain and six other strains tested fermented galactose, one strain fermented sorbose, and fermentation of inulin was variable among the strains. Adonitol and glycerol were not fermented, urease was not detected, and gluconate was not used. Ammonia was not produced in PY or CM cultures.

After incubation for 1 to 3 days, the $\mathrm{pH}$ in PY-glucose cultures was 4.8 to 5.0.

Fermentation products. Fermentation products (average milliequivalents per $100 \mathrm{ml}$ of culture) were as follows.

From PY-glucose: Acetic acid (7.3) and ethanol; also, trace to moderate amounts of lactic and succinic acids were sometimes detected.

From PY-pyruvate: Acetate (5.5) and ethanol.

From PY-fructose: Moderate to abundant hydrogen was detected.

From PY broth: Only trace amounts of acetic acid (when there was growth in PY).

$G+C$ content of the DNA. The $\mathrm{G}+\mathrm{C}$ content of the DNA is $41 \mathrm{~mol} \%$ by $T_{m}$ for the type strain and $40 \mathrm{~mol} \%$ for the one other strain (J18-26) tested.

Type strain. The type strain is ATCC 29174 (= VPI B3-21); it was isolated from human feces.

Comments. The strains placed in this species include: A20-86B, B3-23, J13-2A, J18-26, R2-55, S7A-14, S9A-17, S11-34A, and S12-53 from feces; M3-521B and M4-512 from rectal contents; M6421 from the contents of a transverse colon; and M7-386 from the contents of a descending colon.

Ruminococcus obeum is a rather rigidly defined cluster of strains within the previously more broadly defined species Peptostreptococcus productus. The production of very large amounts of acetate with ethanol, hydrogen, and $\mathrm{CO}_{2}$ is a distinguishing characteristic of this species. By comparison, $P$. productus usually produces less acetic acid and more succinic, lactic, and/or formic acids. Also, strains of $R$. obeum usually do not produce acid from inositol, mannitol, melezitose, starch, or trehalose, although an occasional strain may ferment one of these sugars. All strains of $R$. obeum produce acid from arabinose, cellobiose, fructose, glucose, lactose, maltose, mannose, melibiose, raffinose, rhamnose, ribose, sucrose, and xylose.

This species of anaerobic, gram-positive cocci is placed in the genus Ruminococcus because it grows poorly, if at all, without a fermentable carbohydrate and because its fermentation products are primarily acetic and formic acids, sometimes with small amounts of lactic and succinic acids. Also, the $\mathrm{G}+\mathrm{C}$ content of the DNA from $R$. obeum is within the range reported for other species in Ruminococcus.

Eubacterium dolichum sp. nov. (Gr. adj. do'li.chum [do'li.kum] long [referring to the long chains formed in broth cultures]). Obligately anaerobic, nonsporeforming, nonmotile, thin, gram-positive rods in long chains. The ends of the cells are usually slightly tapered (Fig. 7). From PY-glucose broth cultures, cells were about 0.4 to $0.6 \mu \mathrm{m}$ wide and 1.6 to $6.0 \mu \mathrm{m}$ long.

Colonies. After incubation for 5 days in RGCA roll tubes, subsurface colonies were 0.2 to $0.5 \mathrm{~mm}$ in diameter, lenticular, and transparent to translucent. Surface colonies on BHIA-S roll streaks were 0.5 to $1.5 \mathrm{~mm}$ in diameter, circular, entire, convex, opaque to translucent, granular, dull, and smooth. None of the four strains tested grew on anaerobically incubated BAP. Three of the four strains tested grew on EYA plates but produced no reaction.

Cultural characteristics. Broth cultures had a stringy to ropy sediment without marked turbidity. In general, growth was poor in most of the PY broth media. Growth was often enhanced, although the $\mathrm{pH}$ was not necessarily lowered, in PY broth containing fructose, glucose, maltose, starch, or sucrose. Neither pyruvate nor gluconate was utilized. Best growth was obtained at $37 \mathrm{C}$, although most strains grew at $45 \mathrm{C}$, and there was some growth at $30 \mathrm{C}$.

After incubation for 5 days, the lowest $\mathrm{pH}$ observed in carbohydrate media was 5.9 to 6.0 .

Biochemical reactions. The biochemical characteristics of 11 isolates of this species are reported in Table 3 . In addition, the type strain and three other strains tested did not ferment adonitol, galactose, glycerol, inulin, or sorbose. Ammonia was not produced in PY broth cultures; a small amount was sometimes present in $\mathrm{CM}$ cultures.

Fermentation products. Fermentation prod- 
ucts (average milliequivalents per $100 \mathrm{ml}$ of culture) were as follows.

From PY-glucose: Butyric acid (0.4), usually with lactic acid (0.5) and sometimes with trace amounts of succinic, pyruvic, and acetic acids.

From PY-fructose: Trace amounts of hydrogen were sometimes detected.

From PY broth: Usually there were no detectable acid products or there was only a trace of acetic acid.

$G+C$ content of the DNA. The $\mathrm{G}+\mathrm{C}$ content was not ascertained because the species grew so poorly that we were unable to get a sufficient quantity of cells for this analysis.

Type strain. The type strain is ATCC 29143 (= VPI C9-20); it was isolated from human feces.

ATCC strain 29144 (= VPI S1-30) of E. dolichum was also isolated in this study.

Comments. This organism was described previously (9) under the designation Eubacterium N-1.

All 11 isolates of this species were from human feces, and they include C9-21A, C35-10D, C48-42, S1-30, S4E-25, and J21-54B.

This species is most easily recognized by the long chains of cells produced, the relatively low metabolic activity, and the production of small amounts of butyrate. Because $E$. dolichum is composed of obligately anaerobic, nonsporeforming, gram-positive rods that produce butyrate as a major fermentation acid, it is placed in the genus Eubacterium.

Eubacterium hadrum sp. nov. (Gr. adj. had'rum thick, bulky [referring to the relatively large size of the cell]). Obligately anaerobic, nonsporeforming, nonmotile, gram-positive rods of uniform width, with rounded ends, occurring in pairs and short chains (Fig. 8). From PY-glucose broth cultures, cells were about 0.7 to $1.0 \mu \mathrm{m}$ wide and 3.0 to $10.0 \mu \mathrm{m}$ long.

Colonies. After incubation for 5 days in RGCA roll tubes, subsurface colonies were woolly balls 1 to $2 \mathrm{~mm}$ in diameter. Surface colonies on BHIA-S roll streaks and anaerobically incubated BAP were 2 to $3 \mathrm{~mm}$ in diameter, circular, entire to erose, convex, opaque to translucent, and smooth. Some strains produced slight greening hemolysis on BAP; there was no reaction on EYA.

Cultural characteristics. PY-glucose broth cultures had abundant growth and were turbid with smooth, sometimes ropy, sediment. 'There was good growth at 37 and at $45 \mathrm{C}$, but lesser growth at $30 \mathrm{C}$.

Biochemical reactions. Characteristics of 18 isolates are reported in Table 3 . In addition, the type strain and 10 other strains tested fer-

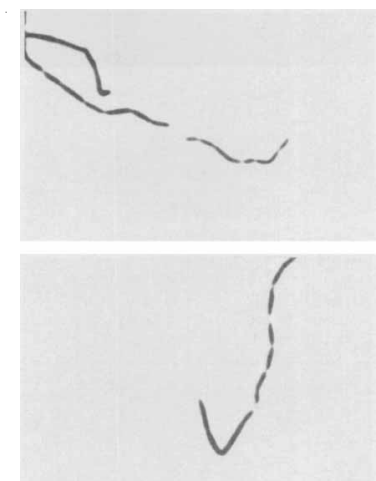

FIG. 7. Eubacterium dolichum ATCC 29143. Top, Cells from PY broth culture. Bottom, Cells from PY-glucose broth culture. See Fig. 11 for scale.

mented galactose and inulin; sorbose was fermented by the majority of the strains. Adonitol and glycerol were not fermented, urease was not detected, and ammonia was not produced in PY broth cultures. A few strains produced detectable ammonia in CM cultures.

After incubation for one day, the $\mathrm{pH}$ in $\mathrm{PY}$ glucose cultures was 4.7 to 5.4 .

Fermentation products. Fermentation products (average milliequivalents per $100 \mathrm{ml}$ of culture) were as follows.

From PY-glucose: Butyric acid (4.0), often with small amounts of acetic, propionic, formic, and/or pyruvic acids. Moderate to major amounts of lactic acid sometimes accumulated.

From PY-pyruvate: Acetate (3.5) and butyrate $(3.0)$.

From PY broth: Moderate amounts of butyric acid usually accumulated.

From PY-fructose: Abundant hydrogen was produced.

$G+C$ content of the DNA. The $\mathrm{G}+\mathrm{C}$ content of the DNA is $32 \mathrm{~mol} \%$ by $T_{m}$ for the type strain and $33 \mathrm{~mol} \%$ for the one other strain (S6-14) tested.

Type strain. The type strain is ATCC 29173 (= VPI B2-52); it was isolated from human feces.

Comments. All 18 isolates of this species were from human feces, and these included B247B, C49-43, C53-8, J20-38A, S1A-40B, S4C-47, S5B-44, S6-14, S10A-49, T2-40, and X4-35A.

Although $E$. hadrum has large cells typical of those found in many species of Clostridium, and even though slight swellings in the cells were very occasionally observed, we were unable either to see any typical spores or to demonstrate any heat resistance at $80 \mathrm{C}$ for $10 \mathrm{~min}$.

Because this species is an anaerobic, grampositive, nonsporeforming rod that produces butyric acid, it is placed in the genus Eubacterium. Production of butyric as the only major 


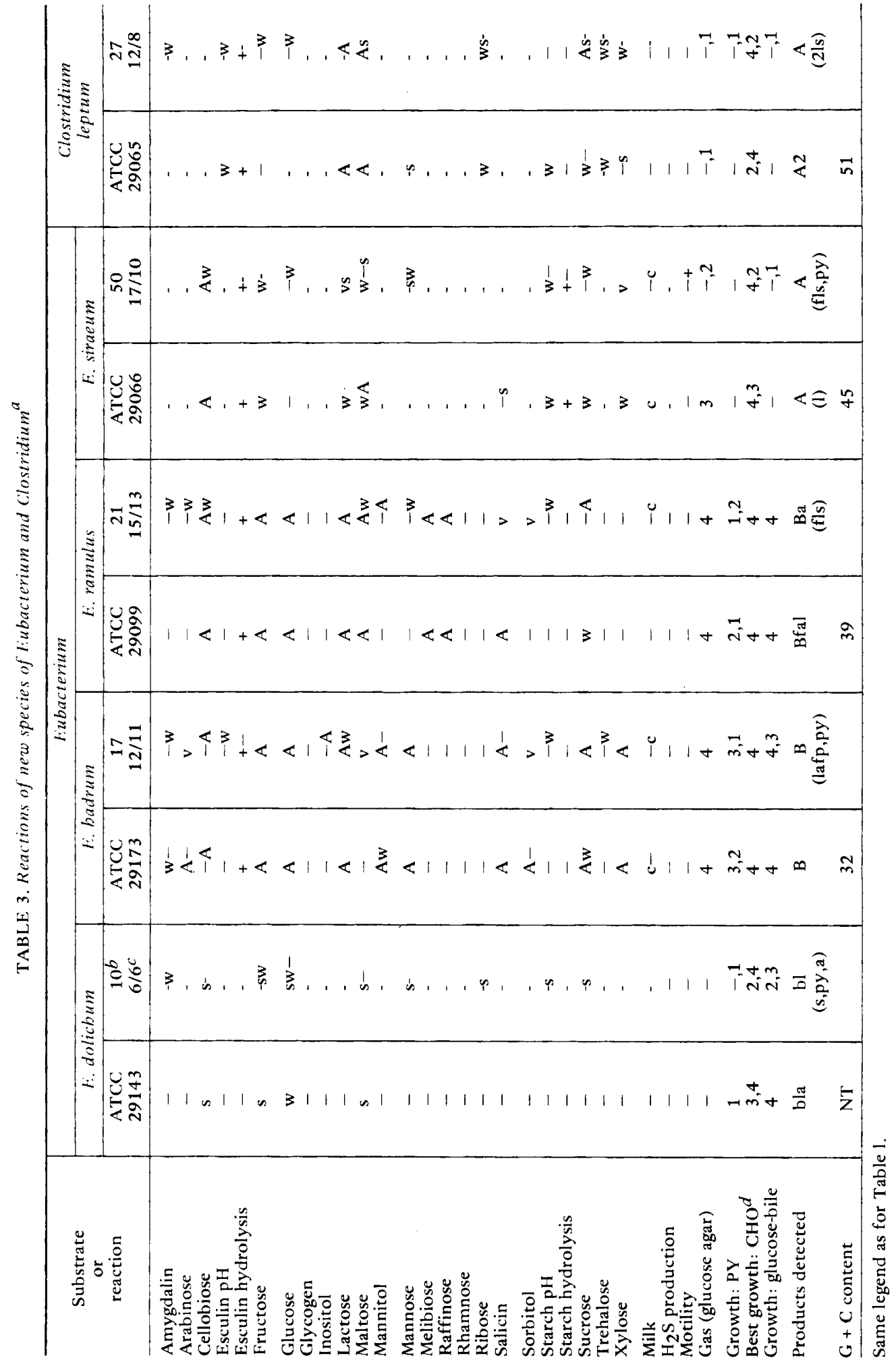




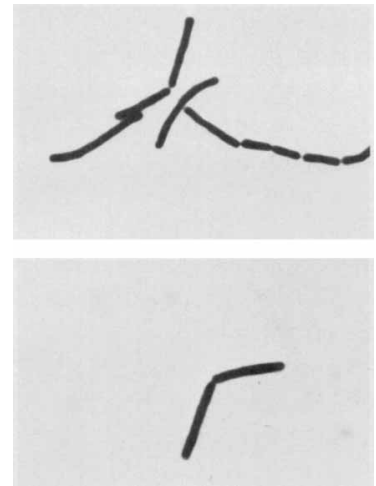

FIG. 8. Eubacterium hadrum ATCC 29173. Top, Cells from $P Y$ broth culture. Bottom, Cells from $P Y$ glucose broth culture. See Fig. 11 for scale.

fermentation acid, large cell size, and fermentation of mannose, sucrose, and (usually) mannitol help differentiate $E$. hadrum from other species in the genus.

Eubacterium ramulus sp. nov. (L. n. ra'mu.lus twig [referring to the shape of the cell]). Obligately anaerobic, nonsporeforming, nonmotile, gram-positive, regular rods with rounded ends, usually staining boldly in young cultures (Fig. 9). Cells occurred in pairs or short chains; long filaments that appeared to be undivided cells or long chains of distinct cells could be seen in some cultures. Cells in the long chains often were of unequal length and occasionally had marked swellings. From PY-glucose broth cultures, cells were about 0.5 to $0.9 \mu \mathrm{m}$ wide and 1.0 to $5.0 \mu \mathrm{m}$ long with filaments exceeding $25.0 \mu \mathrm{m}$ in length.

Colonies. After incubation for 5 days in RGCA roll tubes, subsurface colonies were 1 to $4 \mathrm{~mm}$ in diameter and had the appearance of woolly balls or "balls of fuzz" or were "cauliflower-like" or sometimes of such indefinite form that there was doubt that the area picked (under $\times 10$ magnification) truly contained a colony. Surface colonies on BHIA-S roll streak tubes were 1 to $4 \mathrm{~mm}$ in diameter, circular to slightly irregular, entire or slightly lobate, raised to low convex or umbonate, translucent, and white to beige. Three of eight strains tested did not grow on the surface of anaerobically incubated BAP or EYA plates. When there was growth, there was no reaction on EYA and no hemolytic activity.

Cultural characteristics. In PY-glucose broth there was good growth, usually without turbidity but with stringy or flocculent sediment. Best growth was reliably obtained at $37 \mathrm{C}$, although most strains grew equally well at 30 and $45 \mathrm{C}$ and grew poorly at $25 \mathrm{C}$.

Biochemical reactions. The biochemical characteristics of 21 isolates of this species are reported in Table 3 . In addition, the type strain and eight other strains tested fermented galactose but did not ferment adonitol, glycerol, inulin, or sorbose. Urease was not detected. Ammonia usually was not detected from PY or CM broth cultures.

After incubation for 1 day, the $\mathrm{pH}$ in $\mathrm{PY}$ glucose cultures was 5.0 to 5.4 .

Fermentation products. Fermentation products (average milliequivalents per $100 \mathrm{ml}$ of culture) were as follows.

From PY-glucose: Butyric acid (3.4), acetic acid (0.4), usually formic acid (0.7), lactic acid $(0.6)$, and a trace amount of succinic acid.

From PY-pyruvate: Butyrate (2.3), acetate (2.0), and occasionally formate $(0.2)$.

From PY: Trace to moderate amounts of butyric acid, sometimes with acetic acid, were usually detected.

From PY-fructose: Abundant hydrogen was detected.

$G+C$ content of the DNA. The $\mathrm{G}+\mathrm{C}$ content of the DNA is $39 \mathrm{~mol} \%$ by $T_{m}$ for the type strain and for the one other strain (B4-32) tested.

Type strain. The type strain is ATCC 29099 (= VPI C6-27); it was isolated from human feces.

Comments. This group was described previously (9) under the designation Eubacterium $\mathrm{U}$.

Some of the strains included in this species are: A2-42D, B4-32, C6-27, C14-31, C15-49, C3519, J8-75, J12-14, S1A-47, S4-26, and S7-55A from feces; M5-439 from rectal contents; and M7-485 from scrapings of an ileum wall.

Although swellings were sometimes seen in Gram stains, no cells that survived heating at $80 \mathrm{C}$ for 10 min could be demonstrated in cultures from which these Gram stains had been prepared.

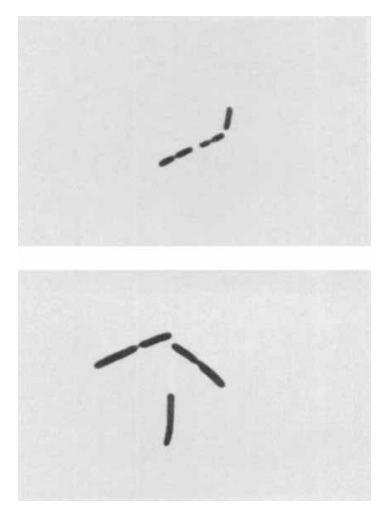

FIG. 9. Eubacterium ramulus ATCC 29099. Top, Cells from $P Y$ broth culture. Bottom, Cells from $P Y$ glucose broth culture. See Fig. 11 for scale. 
Because this species is an anaerobic, grampositive, nonsporeforming rod that produces butyrate, it is placed in the genus Eubacterium. Cell shape and fermentation of cellobiose, melibiose, and raffinose help differentiate $E$. ramulus from other species of Eubacterium that produce large quantities of butyric acid from carbohydrates.

Eubacterium siraeum sp. nov. (Gr. adj. si.rae'um [si.re'um] sluggish [referring to the relative inactivity of this organism in most substrates tested]). Obligately anaerobic, nonsporeforming, gram-positive rods, usually slightly curved, occurring singly, in pairs or short chains, sometimes in "V" or "flying-gull" arrangements (Fig. 10). Some strains were motile with one or two subpolar flagella. Cells were about 0.5 to $0.6 \mu \mathrm{m}$ wide by 1.3 to $6.0 \mu \mathrm{m}$ long.

Colonies. After incubation for 5 days in RGCA roll tubes, colonies were 0.5 to $1.0 \mathrm{~mm}$ in diameter, lenticular, translucent, and tan or white. Larger colonies often had a dense center. Surface colonies on BHIA-S roll streaks or anaerobically incubated BAP were $0.5 \mathrm{~mm}$ in diameter, circular, entire, low convex, smooth, shiny, and transparent to translucent. There was no reaction on EYA and no hemolytic activity. Three of eight strains tested did not grow on anaerobically incubated BAP.

Cultural characteristics. There was no turbidity in PY broth cultures without a fermentable carbohydrate. In the presence of a fermentable carbohydrate, broth cultures were slightly turbid with a smooth sediment. Most strains grew equally well at 37 and $45 \mathrm{C}$; there was little if any growth at $30 \mathrm{C}$. Addition of 10 to $30 \%(\mathrm{vol} / \mathrm{vol})$ rumen fluid stimulated growth of most strains.

Biochemical reactions. The biochemical characteristics of 50 isolates of this species are reported in Table 3. In addition, the type strain

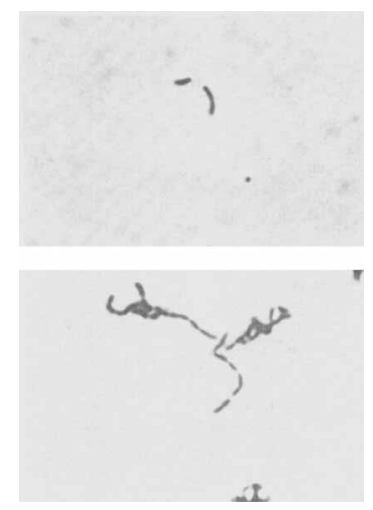

FIG. 10. Eubacterium siraeum ATCC 29066. Top, Cells from PY broth culture. Bottom, Cells from PY-glucose broth culture, See Fig. 11 for scale. and seven other strains tested did not appear to grow in adonitol, galactose, glycerol, inulin, or sorbose. Small amounts of ammonia were produced from CM by some strains. Pyruvate and gluconate were not utilized.

After incubation for 5 days, PY-cellobiose broth cultures had a pH of 5.1 to 5.6.

Fermentation products. Fermentation products (average milliequivalents per $100 \mathrm{ml}$ of culture) were as follows.

From PY-cellobiose: Acetic acid (2.4).

Abundant hydrogen was produced from cellobiose, fructose, or starch.

$G+C$ content of the DNA. The $\mathrm{G}+\mathrm{C}$ content of the DNA is $45 \mathrm{~mol} \%$ by $T_{m}$ for the type strain and for the one other strain (A11-17) tested.

Type strain. The type strain is ATCC 29066 (= VPI T9-50); it was isolated from human feces.

Comments. All isolates we have of this species were from human feces, and they include A6-31, A10-29A, A11-17, R3-13, R8-47B, S6F-46, S7A-55B, S9A-54, S11-54, and T9-50.

Although there was no turbidity without a fermentable carbohydrate, the fact that esculin was frequently hydrolyzed when no turbidity could be seen suggests that there was a slight amount of growth in peptone medium. Cells could be seen in Gram stains from PY cultures, which also suggests that some cell multiplication may occur in the basal medium.

This species of anaerobic, gram-positive, nonsporeforming rods is placed in the genus Eubacterium because acetate or acetate and formate (occasionally) are the sole major fermentation acids. Phenotypically, this species most closely resembles Clostridium leptum but differs from C. leptum by actively fermenting cellobiose, by not producing spores, and by having a $\mathrm{G}+\mathrm{C}$ content of $45 \mathrm{~mol} \%$ as compared with $51 \mathrm{~mol} \%$ for C. leptum.

Clostridium leptum sp. nov. (Gr. adj. lep'tum thin, delicate [referring to the morphological appearance of the cells]). Obligately anaerobic, sporeforming, small, slightly curved, gram-positive rods occurring in pairs or short chains (Fig. 11). The oval, nearly terminal spores were rarely seen. Heat-resistant cells were most often demonstrated from a 3-weekold CM slant culture inoculated into maltose broth which was then heated at $80 \mathrm{C}$ for 10 min. From PY-glucose broth cultures, cells were about 0.6 to $0.8 \mu \mathrm{m}$ wide and 1.3 to 2.8 $\mu \mathrm{m}$ long.

Colonies. After incubation for 5 days in RGCA roll tubes, subsurface colonies were 0.2 to $0.5 \mathrm{~mm}$ in diameter, white, and lenticular to raspberry shaped. Some colonies were of such indefinite form that there was doubt that the 


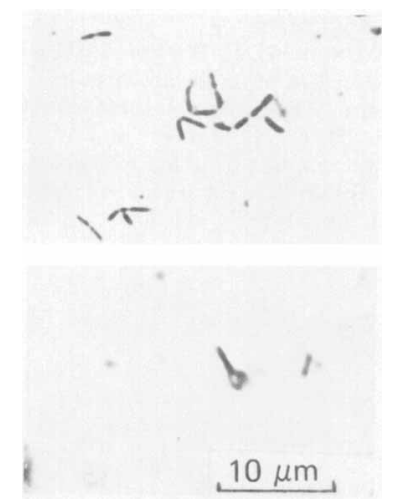

FIg. 11. Clostridium leptum ATCC 29065. Top, Cells from PY-fructose broth culture. Bottom, Spore from CM slant.

area picked (under $\times 10$ magnification) truly contained a colony. Surface colonies on BHIA-S roll streak tubes were minute to $0.5 \mathrm{~mm}$ in diameter, circular, entire, low convex, tan, and translucent. Only 2 of 11 strains tested grew on the surface of BAP incubated anaerobically. No hemolysis was detected. No reaction was noted with the 5 of 11 strains that grew on the surface of EYA.

Cultural characteristics. Broth cultures showed smooth to stringy sediment, usually without turbidity. Growth was markedly stimulated by the presence of some carbohydrates (Table 3), even though the $\mathrm{pH}$ of the medium was not appreciably lowered in the presence of these carbohydrates. There was poor growth in PY broth without carbohydrate. Best growth was obtained at $37 \mathrm{C}$, although some strains would grow at 30 and $45 \mathrm{C}$.

Biochemical reactions. Characteristics of 27 isolates are reported in Table 3 . In addition, the type strain and 10 other strains tested did not ferment adonitol, galactose, glycerol, inulin, or sorbose. Small amounts of ammonia were occasionally produced in CM cultures. There was no apparent growth and no fermentation acids in pyruvate and gluconate media.

After incubation for 5 days in PY-maltose, the $\mathrm{pH}$ was 5.3 to 5.8 .

Fermentation products. Fermentation products (average milliequivalents per $100 \mathrm{ml}$ of culture) were as follows.

From PY-maltose: Acetic acid (2.0) and copious hydrogen.

$G+C$ content of the DNA. The $\mathrm{G}+\mathrm{C}$ content of the DNA is $51 \mathrm{~mol} \%$ by $T_{m}$ for the type strain and $52 \mathrm{~mol} \%$ for the one other strain (B8-26) tested.

Type strain. The type strain ATCC 29065 (= VPI T7-24); it was isolated from human feces.

Comments. Strains included in this species are J8-21, B8-27, R7-49, S6F-42, T7-29, X4-45, and M4-553 from feces or rectal contents and M6-436 from descending-colon contents.

Esculin hydrolysis often took place, even when there was no apparent turbidity or sediment in the culture.

Because this species is obligately anaerobic and produces spores, it is placed in the genus Clostridium. Phenotypically, it is unlike any other described species in the genus. It most closely resembles $E$. siraeum, from which it differs in $\mathrm{G}+\mathrm{C}$ content of the DNA, production of spores, and lack of cellobiose fermentation.

\section{ACKNOWLEDGMENTS}

We gratefully acknowledge the support of this work by the Public Health Service (National Institute of General Medical Sciences grant 14604; National Cancer Institute contract NO1-CP-33334) and by the National Aeronautics and Space Administration (contract NASA 9-12601).

We are indebted to Thomas $O$. MacAdoo of the Foreign Language Department of this institution for providing appropriate specific epithets for the species described. We especially appreciate the technical assistance of Loretta Albert, Roger Cook, Maeve Crowgey, Pauletta Cumbee, Ann Donnelly, Linda Hoffman, Dan Linn, Steven Lowe, Carol Phelps, Christina Spittle, Barbara Thompson, Dianne Wall, and others of our laboratory who performed work on or for this project. We thank Elizabeth P. Cato for help in compilation of the data, and M. P. Bryant for suggestions concerning analysis of Desulfomonas pigra.

\section{REPRINT REQUESTS}

Address reprint requests to: W. E. C. Moore, Anaerobe Laboratory, Virginia Polytechnic Institute and State University, P.O. Box 49, Blacksburg, Va. 24060

\section{LITERATURE CITED}

1. Bryant, M. P. 1974. Genus Butyrivibrio, p. 420. In R. E. Buchanan, and N. E. Gibbons (ed.), Bergey's manual of determinative bacteriology. The Williams and Wilkins Co., Baltimore.

2. Bryant, M. P., and N. Small. 1956. The anaerobic monotrichous butyric acid-producing curved rod-shaped bacteria of the rumen. J. Bacteriol. 72:16-21.

3. Holdeman, L. V., I. J. Good, and W. E. C. Moore. 1976. Human fecal flora: variation in bacterial composition within individuals and a possible effect of emotional stress. Appl. Environ. Microbiol. 31:359-375.

4. Holdeman, L. V., and W. E. C Moore. 1974. New genus Coprococcus, twelve new species, and emended descriptions of four previously described species of bacteria from human feces. Int. J. Syst. Bacteriol. 24:260-277.

5. Holdeman, L. V., and W. E. C. Moore (ed.). 1975. Anaerobe laboratory manual, 3rd ed., p. 11-128. Anaerobe Laboratory, Virginia Polytechnic Institute and State University, Blacksburg.

6. Jackson, F. L., Y. E. Goodman, F. R. Bel, P. C. Wong, and R. L. S. Whitehouse. 1971. Taxonomic status of facultative and strictly anaerobic "corroding bacilli" that have been classified as Bacteroides corrodens. J. Med. Microbiol. 4:171-184.

7. Leatherwood, J. M., and M. P. Sharma. 1972. Novel anaerobic cellulolytic bacterium. J. Bacteriol. 110:751-753.

8. Marmur, J., and P. Doty, 1962. Determination of the base composition of deoxyribonucleic acid from its 
thermal denaturation temperature. J. Mol. Biol. 5:109-118.

9. Moore, W. E. C., and L. V. Holdeman. 1974. Human fecal flora: the normal flora of 20 Japanese-Hawaiians. Appl. Microbiol. 27:961-979.

10. Rogosa, M. 1974. Genus Ruminococcus, p. 518. In R. E. Buchanan and N. E. Gibbons (ed.), Bergey's manual of determinative bacteriology. The Williams and Wil- kins Co., Baltimore.

11. Wilkins, T. D., and C. B. Walker. 1975. A micromethod for identification of anaerobic bacteria: development of procedure. Appl. Microbiol. 30:825-830.

12. Wilkins, T. D., C. B. Walker, and W. E. C. Moore. 1975. A micromethod for identification of anaerobic bacteria: design and operation of apparatus. Appl. Microbiol. 30:831-837. 